\title{
Accounting for slacks to measure dynamic inefficiency in data envelopment analysis
}

\author{
Juan Aparicio ${ }^{\mathrm{a}}$, Magdalena Kapelko ${ }^{\mathrm{b}, *}$ \\ ${ }^{a}$ Center of Operations Research (CIO), Miguel Hernandez University of Elche (UMH), Elche (Alicante), Spain \\ ${ }^{\mathrm{b}}$ Department of Logistics, Institute of Applied Mathematics, Wrocław University of Economics, Wrocław, Poland
}

\section{A R T I C L E I N F O}

\section{Article history:}

Received 20 July 2017

Accepted 28 August 2018

Available online 1 September 2018

\section{Keywords:}

Data envelopment analysis

Dynamic inefficiency

Weighted additive model

Slacks

Dairy manufacturing industry

\begin{abstract}
A B S T R A C T
Slacks that arise when nonparametrically constructing technologies are relevant because they can be an important source of technical inefficiency. This paper extends the measurement of dynamic inefficiency in the full input-output space in the adjustment-cost theory framework to account for slacks. In particular, the paper develops the dynamic weighted additive model in Data Envelopment Analysis (DEA) and shows its main properties. Additionally, the approach is illustrated by a real application. The empirical application concerns data on large firms in the dairy-manufacturing industry in the main dairy-producing countries in the European Union (France, Germany, Italy, Spain, Poland, and the Czech Republic) from 2005 to 2012. The results show the differences in average dynamic inefficiency between the analyzed countries. The findings also indicate that, not surprisingly, firms are, on average, closer to their own-country frontier than the common frontier comprising all firms, regardless of country. Greater inefficiency was also found, on average, in the new approach when related to the dynamic framework that does not account for slacks.
\end{abstract}

(c) 2018 Elsevier B.V. All rights reserved.

\section{Introduction}

The measurement of production (in)efficiency attracts considerable attention in the scientific literature, as it is a relevant topic for managers and policy-makers. ${ }^{1}$ Since Farrell's (1957) work showing how to empirically estimate production functions enveloping all observations in the sample, research on inefficiency measurement focuses on developing and applying static inefficiency models through the nonparametric method of data-envelopment analysis (DEA) (Charnes, Cooper, \& Rhodes, 1978; Banker, Charnes, \& Cooper, 1984) or parametric approaches of deterministic and stochastic frontier models (Aigner \& Chu, 1968; Aigner, Lovell, \& Schmidt, 1977). Static models of inefficiency ignore the dynamic interdependence of firms' production decisions over time and treat firms' capital and other quasi-fixed inputs as fixed. If there is dynamic interdependence, assuming a static theory of production results in biased measurements of inefficiency.

More recent inefficiency literature, both in DEA and parametric contexts, recognizes the importance of modelling the dynamics of

\footnotetext{
* Corresponding author.

E-mail address: magdalena.kapelko@ue.wroc.pl (M. Kapelko).

1 This line of research uses both the terms efficiency and inefficiency, as firms' performance can be analyzed from two sides as either degree of efficiency or inefficiency achieved by the firm. Because the models we develop in this paper define firms' performance in terms of inefficiency, we used the term inefficiency in the preceding parts of this paper.
}

firms' production decisions (Serra, Oude Lansink, \& Stefanou, 2011; Silva, Oude Lansink, \& Stefanou, 2015; Kapelko, Oude Lansink, \& Stefanou, 2014; Fallah-Fini et al., 2014; Tone \& Tsutsui, 2010, 2014). Despite different approaches developed to measure dynamic inefficiency of production, one can broadly classify them into two main groups.

The first group of studies, initiated by Shephard and Färe (1975), Sengupta (1995), and Färe and Grosskopf (1996) rely on the idea of multi-stage production systems, in which some activities are carried over from one period to the next. For example, an output in one period is used as an input for the next, or a quasi-fixed input at the end of the period is treated as an additional output in that period. As such, this group of studies is closely related with network inefficiency models (see Avkiran, 2009; Tone and Tsutsui, 2009). Chronologically speaking, Nemoto and Goto (1999, 2003), Sueyoshi and Sekitani (2005), Chen (2009), Chen and Van Dalen (2010), Tone and Tsutsui (2010, 2014), and Skevas, Oude Lansink, and Stefanou (2012) are all examples of this research line of dynamic inefficiency studies.

The second group of studies employs the adjustment-cost technology framework, in which the dynamic interdependence of firms' production decisions is in the form of adjustment costs. These costs that represent transaction or reorganization costs, such as for learning, arise in this framework from the changes in quasi-fixed factors of production associated with investments in these factors. The pioneering works within this line of research 
include Silva and Stefanou (2003, 2007), subsequently extended by Rungsuriyawiboon and Stefanou (2007), Serra et al. (2011), Kapelko et al. (2014), Ang and Oude Lansink (2014), and Silva et al. (2015), among others. ${ }^{2}$ However, the theory of adjustment costs was developed in the economic and econometric literature some time before the aforementioned works, with key contributions from Treadway (1970), McLaren and Cooper (1980), and Epstein (1981).

In contrast to the parametric literature on efficiency in which measuring technical efficiency is based on a few measures, mainly the Shephard input- and output-distance function (Shephard, 1953) and the directional distance function (Chambers, Chung, \& Färe, 1998), the first years of DEA saw the introduction of many different technical efficiency measures: the Russell input and output measures and the Russell graph measure of technical efficiency (see Färe, Grosskopf, \& Lovell, 1985); the additive model (Charnes, Cooper, Golany, Seiford, \& Stutz, 1985); the weighted additive model (Lovell \& Pastor, 1995); the range-adjusted measure (Cooper, Park, \& Pastor, 1999); the enhanced Russell graph (Pastor, Ruiz, \& Sirvent, 1999); and the slacks-based measure (Tone, 2001), to name but a few. More recent contributions related to the slacks-based measure have been Sueyoshi and Sekitani (2005) and Matin and Ghahfarokhi (2015). One reason for the introduction of many different technical efficiency measures in DEA is the piecewise linear nature of the boundary of the estimated technology. In this context, one notion that comes into play is Pareto-efficiency (Koopmans, 1951), which ultimately means that the efficiency evaluation is performed, accounting for the possible presence of slacks. Input and output slacks are important because they are sources of technical inefficiency that must be considered in terms of not wanting to neglect some causes of underperformance in the data.

However, Pareto-efficiency seems not be a problem for the parametric approach, in which the functional forms utilized to model production frontiers are usually smooth. This different set of tools for estimating technical inefficiency in the parametric and nonparametric world reveals the importance in DEA of measuring inefficiency with respect to the Pareto-efficient frontier, a particular subset of the production frontier.

Regarding the literature that relates to both dynamic inefficiency of production and Pareto-efficiency, the only directly related approach of which we are aware is Tone and Tsutsui (2010), which develops a dynamic DEA model that accounts for slacks. However, this paper extends upon Shephard and Färe (1975), Sengupta (1995), and Färe and Grosskopf (1996), by introducing slacks in modeling the effects of carry-over activities between two consecutive periods. Therefore, it does not extend the adjustment costbased dynamic approach, what is particularly proposed in this paper as a new advance in this line.

To sum up, the objective of this paper is to extend the measurement of dynamic inefficiency in the full input-output space in the adjustment-cost framework to account for slacks. The resulting approach is the dynamic weighted additive model that is developed based on the well-known weighted additive model in DEA (Lovell \& Pastor, 1995). The new approach is applied to the data on large firms in the dairy-manufacturing industry in the main dairyproducing countries in the European Union (France, Germany, Italy, Spain, Poland, and the Czech Republic) from 2005 to 2012.

The remainder of this paper is organized as follows: Section 2 provides the notation and a brief revision of the literature about static and dynamic approaches. In Section 3, we introduce a new version of the weighted additive model for measuring technical inefficiency in the dynamic framework.

\footnotetext{
2 The adjustment costs are explicitly modeled in all these works. See De Mateo, Coelli, and O'Donnell (2006) for an implicit consideration of adjustment costs in dynamic inefficiency measurement.
}

Section 4 shows an empirical application of how the new model performs. Section 5 concludes the paper.

\section{Notation and background}

In this section, we introduce the necessary notation and briefly review the basic elements that will be used in the text.

\subsection{The static approach}

Let us consider $n$ DMUs that use $m$ inputs to produce $s$ outputs. These are denoted by $\left(x_{j}, y_{j}\right), j=1, \ldots, n$. It is assumed that $x_{j}=\left(x_{1 j}, \ldots, x_{m j}\right) \in R_{+}^{m}, x_{j} \neq 0_{m}, j=1, \ldots, n$, and $y_{j}=\left(y_{1 j}, \ldots, y_{s j}\right) \in$ $R_{+}^{s}, y_{j} \neq 0_{s}, j=1, \ldots, n$. The relative efficiency of each $\mathrm{DMU}_{0}$ in the sample is traditionally assessed with reference to the production technology, which is defined as follows:

$T=\{(x, y) / x$ can produce $y\}$

Assuming variable returns to scale (VRS), $T$ can be empirically constructed from $n$ observations as follows (Banker et al., 1984):

$$
\begin{gathered}
T=\left\{(x, y) \in R_{+}^{m+s} / x \geq \sum_{j=1}^{n} \lambda_{j} x_{j}, y \leq \sum_{j=1}^{n} \lambda_{j} y_{j},\right. \\
\left.\sum_{j=1}^{n} \lambda_{j}=1, \lambda_{j} \geq 0, j=1, \ldots, n\right\}
\end{gathered}
$$

In the production literature, the concept of frontier is linked to the notion of technology. Specifically, the weakly efficient frontier of $T$ is defined as $\partial^{w}(T):=\{(x, y) \in T: \hat{x}<x, \hat{y}>y \Rightarrow(\hat{x}, \hat{y}) \notin T\}$. Following Koopmans (1951), isolating a certain subset of $\partial^{w}(T)$ is necessary to measure technical efficiency in the Pareto sense. We refer to the strongly efficient frontier of $T$, defined as $\partial^{s}(T):=$ $\{(x, y) \in T: \hat{x} \leq x, \hat{y} \geq y,(\hat{x}, \hat{y}) \neq(x, y) \Rightarrow(\hat{x}, \hat{y}) \notin T\}$. In this way, $\partial^{s}(T)$ is the set of all the Pareto-Koopmans efficient points of $T$, or points for which it is not possible to improve any input or output without worsening some other input or output.

The literature has proposed several measures to determine the technical efficiency of a set of DMUs in the full input-output space in a DEA context. The so-called directional distance function, relevant for its properties (flexibility, duality, units invariance, and translation invariance), is defined as follows (Chambers et al., 1998): ${ }^{3}$

$$
\begin{aligned}
& \vec{D}\left(x_{0}, y_{0} ; g_{0}^{x}, g_{0}^{y}\right)=\max \beta_{0} \\
& \text { s.t. } \\
& \sum_{j=1}^{n} \lambda_{j 0} x_{i j} \leq x_{i 0}-\beta_{0} g_{i 0}^{x}, \quad i=1, \ldots, m \\
& -\sum_{j=1}^{n} \lambda_{j 0} y_{r j} \leq-y_{r 0}-\beta_{0} g_{r 0}^{y}, \quad r=1, \ldots, s \\
& \sum_{j=1}^{n} \lambda_{j 0}=1 \\
& \lambda_{j 0} \geq 0 \text {, } \\
& j=1, \ldots, n
\end{aligned}
$$

\footnotetext{
3 Luenberger $(1992,1995)$ introduced the concept of benefit function as a representation of the amount that an individual is willing to trade, in terms of a specific reference commodity bundle $g$, for the opportunity to move from a consumption bundle to a utility threshold. Luenberger also defined a so-called shortage function (Luenberger, 1992, p. 242, Definition 4.1), which measures the distance in the direction of a vector $g$ of a production plan from the boundary of the production possibility set. In other words, the shortage function measures the amount by which a specific plan is short of reaching the frontier of the technology. Chambers, Chung, and Färe (1998) redefined the benefit function and the shortage function as efficiency measures, introducing the directional distance function.
} 
in which $g=\left(g_{0}^{x}, g_{0}^{y}\right) \in R_{+}^{m} \times R_{+}^{s}$ is a directional vector and $\beta_{0}$ measures the degree of technical inefficiency in the full input-output space of $\mathrm{DMU}_{0}$, with vector of inputs and outputs $\left(x_{0}, y_{0}\right)$. Directional distance function projects any input and output vector onto the technology frontier in a pre-assigned direction, given by the directional vector. Therefore, this measure does not always reach the strongly efficient frontier. It implements the Debreu-Farrell definition of technical efficiency (Debreu, 1951; Farrell, 1957), instead of the Pareto-Koopmans alternative notion (Koopmans, 1951).

The weighted additive (WA) model is another approach for measuring technical inefficiency in the full input-output space (Lovell \& Pastor, 1995). This measure was introduced in the literature to apply the notion of Pareto-efficiency in DEA (see also Charnes et al., 1985):

$$
\begin{aligned}
& W A\left(x_{0}, y_{0} ; w^{x}, w^{y}\right)=\operatorname{Max} \sum_{i=1}^{m} w_{i}^{x} s_{i 0}^{x}+\sum_{r=1}^{s} w_{r}^{y} s_{r 0}^{y} \\
& \text { s.t. } \\
& \sum_{j=1}^{n} \lambda_{j 0} x_{i j}+s_{i 0}^{x} \leq x_{i 0}, \quad i=1, \ldots, m \\
& -\sum_{j=1}^{n} \lambda_{j 0} y_{r j}+s_{r 0}^{y} \leq-y_{r 0}, \quad r=1, \ldots, s \\
& \sum_{j=1}^{n} \lambda_{j 0}=1 \\
& s_{i 0}^{x} \geq 0 \text {, } \\
& s_{r 0}^{y} \geq 0 \text {, } \\
& \lambda_{j 0} \geq 0 \text {, } \\
& i=1, \ldots, m \\
& r=1, \ldots, s \\
& j=1, \ldots, n \text {, }
\end{aligned}
$$

in which $w^{x}=\left(w_{1}^{x}, \ldots, w_{m}^{x}\right) \in R_{++}^{m}$ and $w^{y}=\left(w_{1}^{y}, \ldots, w_{s}^{y}\right) \in R_{++}^{s}$ are weights representing the relative importance of unit inputs and unit outputs. Different paths can be followed in choosing such weights. One possibility selects them, based on the observations. It is then possible to achieve a dimensionless optimal value in (4). This line was first proposed by Lovell and Pastor (1995), followed by Cooper et al. (1999) with the measure of inefficiency proportions (MIP) and the Range-Adjusted Measure (RAM) and, more recently, by Cooper, Pastor, Borras, Aparicio, and Pastor (2011) to introduce the bounded-adjusted measure (BAM).

$W A\left(x_{0}, y_{0} ; w^{x}, w^{y}\right)=\sum_{i=1}^{m} w_{i}^{x} s_{i 0}^{x *}+\sum_{r=1}^{s} w_{r}^{y} s_{r 0}^{y *}$, in which * denotes optimality, represents the technical inefficiency associated with $\mathrm{DMU}_{0}$. The weighted additive model maximizes a weighted $\ell_{1}$ distance from $\mathrm{DMU}_{0}$ to the frontier of the technology, and simultaneously increases outputs and reduces inputs. In contrast to the directional distance function, an important property of the weighted additive model is that it satisfies the Pareto-Koopmans definition of technical inefficiency: $\left(x_{0}, y_{0}\right) \in \partial^{s}(T)$, if and only if $W A\left(x_{0}, y_{0} ; w^{x}, w^{y}\right)=0$ (Cooper et al., 1999).

\subsection{The dynamic approach}

The above models were built on the conventional static approach and did not take into account the investments in capital. The dynamic directional distance function is a different proposal for the conventional directional distance function (3), which encompasses the static approach (Ang \& Oude Lansink, 2014; Kapelko et al., 2014; Kapelko, 2017; Silva et al., 2015) and represents an adjustment-cost production technology. Before showing its mathematical expression in the case of DEA, let us introduce some additional, necessary notions.
We assume that each $\mathrm{DMU}_{\mathrm{j}}, j=1, \ldots, n$, in addition to consume $m$ inputs $^{4} x_{j}=\left(x_{1 j}, \ldots, x_{m j}\right)$, uses a vector of $f$ gross investments in quasi-fixed inputs $I_{j}=\left(I_{1 j}, \ldots, I_{f j}\right)$, and a vector of $f$ quasi-fixed inputs $k_{j}=\left(k_{1 j}, \ldots, k_{f j}\right)$, for producing $s$ outputs $y_{j}=\left(y_{1 j}, \ldots, y_{s j}\right)$. The dynamic production technology transforms variable inputs and gross investments into outputs at a given level of quasi-fixed inputs.

The dynamic directional distance function in the full inputoutput space may be defined as follows (Ang \& Oude Lansink, 2014; Silva et al., 2015):

$$
\begin{aligned}
\vec{D}\left(x_{0}, I_{0}, y_{0}, k_{0} ; g_{0}^{x}, g_{0}^{y}, g_{0}^{I}\right)= & \operatorname{Max} \beta_{0} \\
& \text { s.t. } \sum_{j=1}^{n} \lambda_{j 0} x_{i j} \leq x_{i 0}-\beta_{0} g_{i 0}^{x}, \\
\quad & i=1, \ldots, m \\
& \sum_{j=1}^{n} \lambda_{j 0} y_{r j} \geq y_{r 0}+\beta_{0} g_{r 0}^{y}, \quad r=1, \ldots, s \\
& \sum_{j=1}^{n} \lambda_{j 0}\left(I_{h j}-\delta_{h} k_{h j}\right) \geq\left(I_{h 0}-\delta_{h} k_{h 0}\right) \\
& +\beta_{0} g_{h 0}^{I}, \quad h=1, \ldots, f \\
& \sum_{j=1}^{n} \lambda_{j 0}=1, \\
& \lambda_{j 0} \geq 0, \quad j=1, \ldots, n
\end{aligned}
$$

in which $\delta_{h}$ denotes depreciation rates, which are specific for each type of investment, and $g_{i 0}^{x}$ is a directional vector for variable inputs, $g_{r 0}^{y}$ is a directional vector for outputs and $g_{h 0}^{I}$ is a directional vector for gross investments ${ }^{5}$. The dynamic directional distance function is defined by simultaneously contracting variable inputs, and expanding outputs and gross investments. $\beta_{0}$ measures the degree of dynamic technical inefficiency in the full input-output space of $\mathrm{DMU}_{0}$.

Fig. 1 illustrates how the dynamic directional distance function works, assuming one variable input $x$, one dynamic factor (investment), and a fixed output level. In the figure, the bold solid line represents the set of Pareto-Koopmans points, or the strongly efficient frontier, which is a subset of the weakly efficient frontier, represented by the union of the bold solid line and the dashed lines. Point $C$ is projected onto the isoquant (the weakly efficient frontier), following a pre-fixed direction. In particular, Fig. 1 shows three projections, associated with three possible directions: $g 1, g 2$, and g3. Note that directions $g 1$ and $g 2$ project unit $C$ onto $D$ and $E$, respectively, which are non-Pareto efficient points, since both are dominated by unit $A$. Direction $g 3$ is a different case in which unit $C$ is projected onto $F$, which is Pareto-efficient. Therefore, the dynamic directional distance function may not take into account all sources of technical inefficiency (slacks, in the case of the first two directions).

In view of the preceding discussion, the dynamic approach, in contrast to the static approach, has recently attracted the attention of researchers when dynamic factors, such as investment, must be considered in the data analysis. The dynamic directional distance function is one of the preferred approaches for measuring technical inefficiency, due to its flexibility and good properties. However, one of the unsolved challenges is extending this approach to allow for considering all sources of technical inefficiency in the measurement. Therefore, research must be directed at developing at

\footnotetext{
${ }^{4}$ In the case of dynamic models we talk about variable inputs as we distinguish between variable and quasi-fixed inputs.

${ }^{5}$ Notice that in model (5) the quasi-fixed input is incorporated through investment constraint.
} 


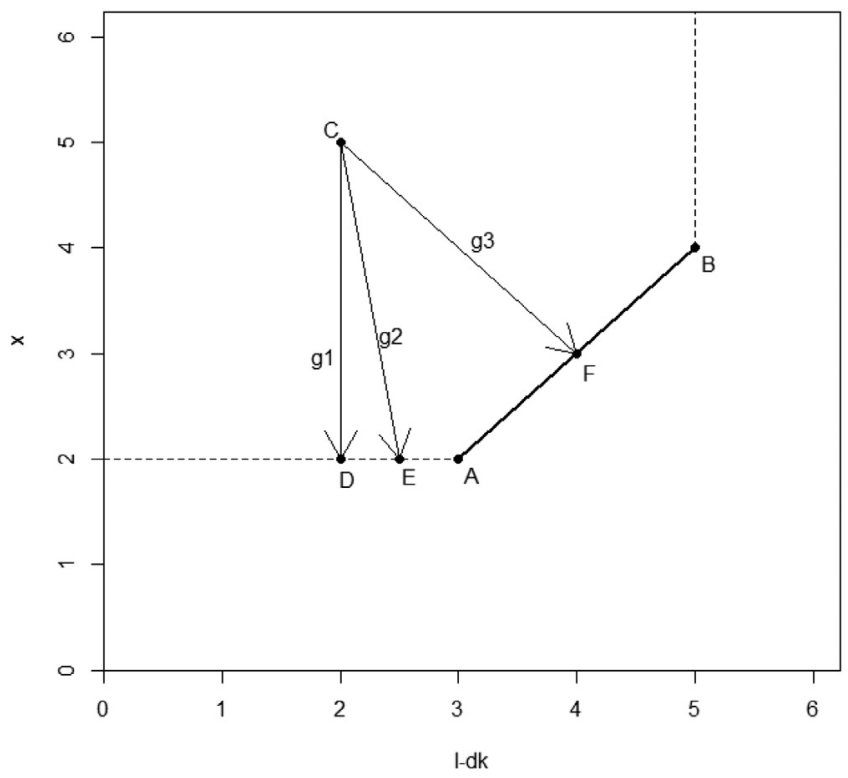

Fig. 1. The dynamic directional distance function.

least a new measure capable of dealing with the notion of Paretoefficiency in a dynamic framework. In the next section, we introduce a new dynamic measure, based on the well-known weighted additive model in DEA.

\section{The dynamic weighted additive model in DEA}

In this section, we introduce a new dynamic measure of technical inefficiency for accounting for slacks in DEA. It is based upon model (4), the weighted additive model by Lovell and Pastor (1995).

In the same context as Section 2.2, the dynamic weighted additive model for determining the technical inefficiency of $\mathrm{DMU}_{0}$, with vector $\left(x_{0}, I_{0}, y_{0}, k_{0}\right)$ in the full input-output space, is defined as follows:

$$
\begin{aligned}
& W A\left(x_{0}, I_{0}, y_{0}, k_{0} ; w_{0}^{x}, w^{y}, w^{I}\right)=\operatorname{Max} \sum_{i=1}^{m} w_{i}^{x} s_{i 0}^{x}+\sum_{r=1}^{s} w_{r}^{y} s_{r 0}^{y} \\
& +\sum_{h=1}^{f} w_{h}^{I} s_{h 0}^{I} \\
& \text { s.t. } \sum_{j=1}^{n} \lambda_{j 0} x_{i j} \leq x_{i 0}-s_{i 0}^{x} \\
& i=1, \ldots, m \\
& \sum_{j=1}^{n} \lambda_{j 0} y_{r j} \geq y_{r 0}+s_{r 0}^{y}, \quad r=1, \ldots, s \\
& \sum_{j=1}^{n} \lambda_{j 0}\left(I_{h j}-\delta_{h} k_{h j}\right) \geq\left(I_{h 0}-\delta_{h} k_{h 0}\right) \\
& +s_{h 0}^{I}, \quad h=1, \ldots, f \\
& \sum_{j=1}^{n} \lambda_{j 0}=1 \\
& \lambda_{j 0} \geq 0 \text {, } \\
& j=1, \ldots, n \\
& s_{i 0}^{X} \geq 0 \text {, } \\
& s_{r 0}^{y} \geq 0 \text {, } \\
& i=1, \ldots, m \\
& s_{h 0}^{I} \geq 0 \text {, } \\
& r=1, \ldots, s \\
& h=1, \ldots, f
\end{aligned}
$$

This maximization problem (6) solves for $\mathrm{DMU}_{0}$, its dynamic technical inefficiency, and its corresponding intensity variables $\lambda_{j 0}$, $j=1, \ldots, n$. The first, second, and third constraints imply strong disposability of inputs, outputs and gross investments, respectively. The assumption of variable returns to scale is reflected by the fourth constraint. The remaining constraints guarantee nonnegativity of the decision variables. The optimal value of (6) coincides with the weighted $\ell_{1}$ distance from the point $\left(x_{0}, I_{0}, y_{0}\right)$ to the boundary of the production technology $T^{D}$. The corresponding weights of this mathematical distance are specifically $w_{0}^{x}, w_{0}^{y}$ and $w_{0}^{I}$ for variable inputs, outputs, and gross investments, respectively. Given that $s_{0}^{x} \geq 0$ is subtracted from $x_{0}, s_{r 0}^{y} \geq 0$ is added to $y_{0}$, and $s_{0}^{I}$ is added to $I_{0}$, this measure is defined by simultaneously contracting variable inputs, and expanding outputs and dynamic factors of gross investments. It is worth adding that using formula (6), in addition to computing inefficiency for all inputs and outputs simultaneously, it is also possible to calculate input-specific and output-specific inefficiencies, that is, inefficiencies with regard to each input employed and output produced by the $\mathrm{DMU}^{6}$.

If we compare the dynamic model (6) with respect to its static version in model (4), the most significant difference is related to the addition of the constraint associated with investment and the term $\sum_{h=1}^{f} w_{h}^{I} s_{h 0}^{I}$ added to the objective function of model (4). Obviously, the dynamic weighted additive model (6) is an extension of the static weighted additive model (4), which also happened with models (3) and (5).

The following lemma will be useful to prove additional results in the text.

Lemma 1. Let $\left(\lambda_{0}^{*}, s_{0}^{x *}, s_{0}^{y *}, s_{0}^{I *}\right)$ be an optimal solution of model (6), then all the constraints in (6) are binding.

Proof. Let us assume that some of the constraints are not binding, such as the first constraint for the inputs $\sum_{j=1}^{n} \lambda_{j 0}^{*} x_{1 j}<$ $x_{10}-s_{10}^{x *}$. We can then define $\left(\lambda_{0}^{*}, \hat{s}_{0}^{x}, s_{0}^{y *}, s_{0}^{I *}\right)$, with $\hat{s}_{10}^{x}=x_{10}-$ $\sum_{j=1}^{n} \lambda_{j 0}^{*} x_{1 j}>s_{10}^{x *}$ and $\hat{s}_{i 0}^{x}=s_{i 0}^{\chi *}$ for $i \neq 1$, and get a feasible solution for model (6). Regarding the objective function $\sum_{i=1}^{m} w_{i}^{x} \hat{s}_{i 0}^{x}+$ $\sum_{r=1}^{s} w_{r}^{y} s_{r 0}^{y *}+\sum_{h=1}^{f} w_{h}^{I} s_{h 0}^{I *}>\sum_{i=1}^{m} w_{i}^{\chi} s_{i 0}^{\chi *}+\sum_{r=1}^{s} w_{r}^{y} s_{r 0}^{y *}+\sum_{h=1}^{f} w_{h}^{I} s_{h 0}^{I *}$, which is a contradiction with the fact that $\left(\lambda_{0}^{*}, s_{0}^{x *}, s_{0}^{y *}, s_{0}^{I *}\right)$ is an optimal solution for model (6). Consequently, all the constraints in (6) must be binding.

Regarding the satisfaction of properties, Färe and Lovell (1978) were the first to propose a set of desirable properties that an ideal efficiency measure should meet, although these were enunciated for the particular case of an input-oriented measure. Pastor et al. (1999) listed similar requirements and suggested some others for approaches devoted to measuring technical inefficiency in the full input-output space (graph measures). In particular, their main properties were (P1), the assessed $\mathrm{DMU}_{0}$ is Pareto-Koopmans efficient if, and only if, the inefficiency measure takes a value of zero; (P2), units invariant; and (P3), strong monotonicity. Specifically, strong monotonicity means that holding all other inputs and outputs constant, an increase in any of its outputs and/or a decrease in any of its inputs will decrease the inefficiency score. Translation invariance is another relevant property, mainly for dealing with negative data (see Pastor and Aparicio, 2015; Aparicio, Pastor, \& Vidal, 2016). Of course, the aforementioned properties were enunciated in the static framework. However, it is possible to extend these properties to the dynamic context by analogy.

We now show the main properties that the dynamic weighted additive model satisfies.

\footnotetext{
${ }^{6}$ Input-specific inefficiencies in a dynamic context were considered by Kapelko, Oude Lansink, and Stefanou (2017). However, this study considered an input-specific framework, and not a full input-output space approach as analyzed here.
} 
Proposition 1. The dynamic weighted additive model meets the following properties.

(i) $W A\left(x_{0}, I_{0}, y_{0}, k_{0} ; w^{x}, w^{y}, w^{I}\right) \geq 0$;

(ii) If $w_{i}^{x}=t\left(x_{i 0}\right), w_{r}^{y}=q\left(y_{r 0}\right)$ and $w_{h}^{I}=p\left(I_{h 0}, k_{h 0}\right)$ are homogeneous functions of degree -1 in their arguments for all $i, r$ and $h$, then Model (6) is units invariant.

(iii) Model (6) is translation invariant.

(iv) $W A\left(x_{0}, I_{0}, y_{0}, k_{0} ; w^{x}, w^{y}, w^{I}\right)$ is strongly monotonic. ${ }^{7}$

Proof. (i) It is a consequence of the non-negativity constraints $\quad s_{i 0}^{x} \geq 0, \quad i=1, \ldots, m, \quad s_{r 0}^{y} \geq 0, \quad r=1, \ldots, s, \quad s_{h 0}^{I} \geq 0$, $h=1, \ldots, f$, and that the expression of the objective function is $\sum_{i=1}^{m} w_{i}^{x} s_{i 0}^{x}+\sum_{r=1}^{s} w_{r}^{y} s_{r 0}^{y}+\sum_{h=1}^{f} w_{h}^{I} s_{h 0}^{I}$. (ii) Without loss of generality, let us assume that the investment $h^{\prime}, h^{\prime}=1, \ldots, f$, and its related quasi-fixed input are transformed as $I_{h^{\prime}} \rightarrow \alpha_{h^{\prime}} I_{h^{\prime}}$ and $k_{h^{\prime}} \rightarrow \alpha_{h^{\prime}} k_{h^{\prime}}$, with $\alpha_{h^{\prime}}>0$. In this way, the related constraint in (6) is transformed into $\sum_{j=1}^{n} \lambda_{j 0}\left(\alpha_{h^{\prime}} I_{h^{\prime} j}-\delta_{h^{\prime}} \alpha_{h^{\prime}} k_{h^{\prime} j}\right) \geq$ $\left(\alpha_{h^{\prime}} I_{h^{\prime} 0}-\delta_{h^{\prime}} \alpha_{h^{\prime}} k_{h^{\prime} 0}\right)+s_{h^{\prime} 0}^{I}$. By Lemma 1, this implies that, at optimum, $s_{h^{\prime} 0}^{I}=\sum_{j=1}^{n} \lambda_{j 0}\left(\alpha_{h^{\prime}} I_{h^{\prime} j}-\delta_{h^{\prime}} \alpha_{h^{\prime}} k_{h^{\prime} j}\right)-\left(\alpha_{h^{\prime}} I_{h^{\prime} 0}-\delta_{h^{\prime}} \alpha_{h^{\prime}} k_{h^{\prime} 0}\right)=$ $\alpha_{h^{\prime}}\left[\sum_{j=1}^{n} \lambda_{j 0}\left(I_{h^{\prime} j}-\delta_{h^{\prime}} k_{h^{\prime} j}\right)-\left(I_{h^{\prime} 0}-\delta_{h^{\prime}} k_{h^{\prime} 0}\right)\right] . \quad$ Regarding the objective function, the term affected by the transformation would remain as $w_{h^{\prime}}^{I} s_{h^{\prime} 0}^{I} \rightarrow$ $p\left(\alpha_{h^{\prime}} I_{h^{\prime} 0}, \alpha_{h^{\prime}} k_{h^{\prime} 0}\right) \alpha_{h^{\prime}}\left[\sum_{j=1}^{n} \lambda_{j 0}\left(I_{h^{\prime} j}-\delta_{h^{\prime}} k_{h^{\prime} j}\right)-\left(I_{h^{\prime} 0}-\delta_{h^{\prime}} k_{h^{\prime} 0}\right)\right]$.

Finally, by the hypothesis of homogeneity of degree -1 of the function $p\left(I_{h^{\prime} 0}, k_{h^{\prime} 0}\right)$, the effect of $\alpha_{h^{\prime}}$ vanishes. (iii) Without loss of generality, let us assume that the investment $h^{\prime}, h^{\prime}=1, \ldots, f$, and its related quasi-fixed input, are transformed as $I_{h^{\prime}} \rightarrow I_{h^{\prime}}+\alpha_{h^{\prime}}$ and $k_{h^{\prime}} \rightarrow k_{h^{\prime}}+\alpha_{h^{\prime}}$ with $\alpha_{h^{\prime}}>0$. In this way, the related constraint in (6) is transformed into $\sum_{j=1}^{n} \lambda_{j 0}\left(I_{h^{\prime} j}+\alpha_{h^{\prime}}-\delta_{h^{\prime}} k_{h^{\prime} j}-\delta_{h^{\prime}} \alpha_{h^{\prime}}\right) \geq$ $\left(I_{h^{\prime} 0}+\alpha_{h^{\prime}}-\delta_{h^{\prime}} k_{h^{\prime} 0}-\delta_{h^{\prime}} \alpha_{h^{\prime}}\right)+s_{h^{\prime} 0}^{I}$, which is equivalent to $\quad \sum_{j=1}^{n} \lambda_{j 0}\left(I_{h^{\prime} j}-\delta_{h^{\prime}} k_{h^{\prime} j}\right)+\sum_{j=1}^{n} \lambda_{j 0} \alpha_{h^{\prime}}-\sum_{j=1}^{n} \lambda_{j 0} \delta_{h^{\prime}} \alpha_{h^{\prime}} \geq$ $\left(I_{h^{\prime} 0}-\delta_{h^{\prime}} k_{h^{\prime} 0}\right)+\alpha_{h^{\prime}}-\delta_{h^{\prime}} \alpha_{h^{\prime}}+s_{h^{\prime} 0}^{I}$. Applying $\sum_{j=1}^{n} \lambda_{j 0}=1$, we get $\sum_{j=1}^{n} \lambda_{j 0}\left(I_{h^{\prime} j}-\delta_{h^{\prime}} k_{h^{\prime} j}\right)+\alpha_{h^{\prime}}-\delta_{h^{\prime}} \alpha_{h^{\prime}} \geq\left(I_{h^{\prime} 0}-\delta_{h^{\prime}} k_{h^{\prime} 0}\right)+\alpha_{h^{\prime}}-$ $\delta_{h^{\prime}} \alpha_{h^{\prime}}+s_{h^{\prime} 0}^{I}$, which is equivalent to $\sum_{j=1}^{n} \lambda_{j 0}\left(I_{h^{\prime} j}-\delta_{h^{\prime}} k_{h^{\prime} j}\right) \geq$ $\left(I_{h^{\prime} 0}-\delta_{h^{\prime}} k_{h^{\prime} 0}\right)+s_{h^{\prime} 0}^{I}$, meaning that the effect of the transformation vanishes due to the hypothesis of VRS. (iv) Let $\left(x_{0}, I_{0}, y_{0}, k_{0}\right)$ and $(\hat{x}, \hat{I}, \hat{y}, \hat{k})$, such that $x_{0} \leq \hat{x}, I_{0} \geq \hat{I}, y_{0} \geq \hat{y}$ and $k_{0} \leq \hat{k}$. In particular, let us assume, without loss of generality, that $I_{h^{\prime} 0}>\hat{I}_{h^{\prime}}$ for some $h^{\prime}=1, \ldots, f$. Let $\left(\lambda_{0}^{*}, s_{0}^{X *}, s_{0}^{y *}, s_{0}^{I *}\right)$ be an optimal solution of model (6) for assessing $\left(x_{0}, I_{0}, y_{0}, k_{0}\right)$. It is then easy to show that $\left(\lambda_{0}^{*}, s_{0}^{x *}, s_{0}^{y *}, s_{0}^{I *}\right)$ is a feasible solution for model (6) for assessing $(\hat{x}, \hat{I}, \hat{y}, \hat{k})$, since $x_{i 0} \leq \hat{x}_{i}$, $i=1, \ldots, m, \quad y_{r 0} \geq \hat{y}_{r}, \quad r=1, \ldots, s, \quad$ and $\quad I_{h 0}-\delta_{h} k_{h 0} \geq \hat{I}_{h}-\delta_{h} \hat{k}_{h}$, $h=1, \ldots, f$. From $\left(\lambda_{0}^{*}, s_{0}^{x_{*}}, s_{0}^{y *}, s_{0}^{I *}\right)$, we can define another feasible solution of model (6) for assessing $(\hat{x}, \hat{I}, \hat{y}, \hat{k})$ as $\left(\lambda_{0}^{*}, s_{0}^{* *}, s_{0}^{y *}, \hat{s}^{I}\right)$, with $\hat{s}_{h^{\prime}}^{I}=\sum_{j=1}^{n} \lambda_{j 0}^{*}\left(I_{h^{\prime} j}-\delta_{h^{\prime}} k_{h^{\prime} j}\right)-\left(\hat{I}_{h^{\prime}}-\delta_{h^{\prime}} \hat{k}_{h^{\prime}}\right)$ and $\hat{s}_{h}^{I}=s_{h 0}^{I *}$ for $h \neq h^{\prime}$. Note that $\hat{s}_{h^{\prime}}^{I}=\sum_{j=1}^{n} \lambda_{j 0}^{*}\left(I_{h^{\prime} j}-\delta_{h^{\prime}} k_{h^{\prime} j}\right)-$ $\left(\hat{I}_{h^{\prime}}-\delta_{h^{\prime}} \hat{k}_{h^{\prime}}\right)>\sum_{j=1}^{n} \lambda_{j 0}^{*}\left(I_{h^{\prime} j}-\delta_{h^{\prime}} k_{h^{\prime} j}\right)-\left(I_{h^{\prime} 0}-\delta_{h^{\prime}} k_{h^{\prime} 0}\right) \quad$ because $I_{h^{\prime} 0}-\delta_{h^{\prime}} k_{h^{\prime} 0}>\hat{I}_{h^{\prime}}-\delta_{h^{\prime}} \hat{k}_{h^{\prime}}$, which means that $\hat{s}_{h^{\prime}}^{I}>s_{h^{\prime} 0}^{I *}$, since $s_{h^{\prime} 0}^{I *}=$ $\sum_{j=1}^{n} \lambda_{j 0}^{*}\left(I_{h^{\prime} j}-\delta_{h^{\prime}} k_{h^{\prime} j}\right)-\left(I_{h^{\prime} 0}-\delta_{h^{\prime}} k_{h^{\prime} 0}\right)$ by Lemma 1. Finally, regarding the objective function of model (6) for assessing $(\hat{x}, \hat{I}, \hat{y}, \hat{k})$, we have that $W A\left(\hat{x}, \hat{I}, \hat{y}, \hat{k} ; w^{x}, w^{y}, w^{I}\right)=\sum_{i=1}^{m} w_{i}^{x} s_{i 0}^{x *}+\sum_{r=1}^{s} w_{r}^{y} s_{r 0}^{y^{*}}+$ $\sum_{h=1}^{f} w_{h}^{I} \hat{s}_{h}^{I}>\sum_{i=1}^{m} w_{i 0}^{x} s_{i 0}^{x *}+\sum_{r=1}^{s} w_{r 0}^{y} s_{r 0}^{y *}+\sum_{h=1}^{f} w_{h 0}^{I} s_{h 0}^{I *}=W A$ $\left(x_{0}, I_{0}, y_{0}, k_{0} ; w^{x}, w^{y}, w^{I}\right)$, as we were seeking to prove.

\footnotetext{
7 We use the definition of strong monotonicity according to Pastor, Ruiz, and Sirvent (1999) and Cooper et al. (1999). They describe this property as follows: Holding all other inputs and outputs constant, an increase in any of its inputs will increase the inefficiency score for an inefficient $\mathrm{DMU}_{0}$. The same is true for a decrease in any of its outputs.
}

Although there are many alternative weights for the objective function of model (6), we suggest the specific weights $w_{i 0}^{x}=$ $\frac{1}{(m+s+f) \cdot x_{i 0}}, \quad i=1, \ldots, m, \quad w_{r 0}^{y}=\frac{1}{(m+s+f) \cdot y_{r 0}}, \quad r=1, \ldots, s, \quad$ and $w_{h 0}^{I}=$ $\frac{1}{(m+s+f) \cdot 0.2 \cdot k_{h 0}}, h=1, \ldots, f$, for unit $\left(x_{0}, I_{0}, y_{0}, k_{0}\right)$, which are associated with the measure of inefficiency proportions (MIP) (see Cooper et al., 1999). In the case of weights for investments, the formula contains 20 percent of the size of the capital stock, which approximates the size of investments in firms. ${ }^{8}$ With such weights our measure can be interpreted as the average of inefficiency proportions due to excessive inputs, and output and investment shortfalls.

The next section includes an empirical illustration of the use of the new methodology proposed in this paper. We are especially interested in comparing the results generated by the dynamic weighted additive model with those obtained from the dynamic directional distance function.

\section{Empirical application}

\subsection{Dataset}

Our data consist of annual observations for large dairymanufacturing firms in six EU countries from 2005 to 2012. AMADEUS dataset (Bureau van Dijk) is the source of our data. Large firms have more than 250 employees with an annual turnover that exceeds $€ 50$ million, which follows from the EU definition of firm size (European Commission, 2003). Limiting the study to large firms provides in a homogenous sample, which is important for inefficiency analysis using DEA. We chose the main dairy-producing countries in the EU within each geographical region: Poland and Czech Republic for Eastern Europe; Italy and Spain for Southern Europe; and France and Germany for Western Europe.

The dynamic technology modeled in this study consisted of one output, two variable inputs, one quasi-fixed input, and one gross investment. All variables were measured via accounting data. Output was measured by revenues, which were deflated using the producer price index for food manufacturing. The variable inputs consisted of the material and labor costs, which were deflated by the producer price index for non-durable consumer goods and labor cost index in industry, respectively. The quasi-fixed input was measured as the beginning value of fixed assets in year $t$ (the end value of fixed assets from the previous year) and was deflated using the producer price index for capital goods. Gross investments in fixed assets in year $t$ were calculated as the beginning value of fixed assets in year $t+1$, minus the beginning value of fixed assets in year $t$, plus the beginning value of depreciation in year $t+1$. All price indices used to deflate the aforementioned variables were country-specific and supported by the Eurostat (2017) database. All variables were extracted from the AMADEUS database in local currencies and adjusted using the purchasing power parity (PPP) of the local currency to the US dollar.

The final dataset usable for analysis was obtained by removing missing and outlier observations. This study applied Simar's (2003) approach of outlier detection, which is commonly used for frontier models to determine outliers, based on the application of the method of order-m efficiencies (Cazals, Florens, \& Simar, 2002). Our final sample consisted of an unbalanced panel of 311 large, dairy-manufacturing firms (1,625 observations) in six EU countries from 2005 to 2012. Table 1 reports descriptive statistics for the output, inputs, and investments for the data pooled over all years, separately for each country and region, and for the whole

\footnotetext{
${ }^{8}$ Another option for the weights for investments would be to use the actual values of investments in the formula. We did not use the actual values of investments, given the high heterogeneity in the investment variable (Dakpo, 2015).
} 
Table 1

Descriptive statistics of input-output variables per country and region, and for the whole sample, 2005-2012 (thousands of PPP, as of 2004).

\begin{tabular}{lllllll}
\hline Country & No of obs. & Output & Material costs & Employee costs & Fixed assets & Investments \\
\hline Czech Republic & \multirow{2}{*}{136} & 114721.50 & 87131.60 & 5769.88 & 19138.27 & 2976.28 \\
& & $(85506.91)$ & $(66061.94)$ & $(4983.13)$ & $(18438.25)$ & $(3761.19)$ \\
France & 295 & 262950.50 & 172750.44 & 20562.27 & 48365.31 & 7836.96 \\
& & $(368391.53)$ & $(216919.04)$ & $(29846.84)$ & $(69666.97)$ & $(12300.21)$ \\
Germany & \multirow{2}{*}{349} & 326906.95 & 264807.99 & 22022.35 & 48106.18 & 11729.31 \\
& & $(510372.26)$ & $(421914.95)$ & $(35586.56)$ & $(82012.44)$ & $(31548.54)$ \\
Italy & \multirow{2}{*}{346} & 286055.26 & 171779.79 & 27988.60 & 103416.12 & 14288.40 \\
& & $(716320.18)$ & $(386321.78)$ & $(81282.94)$ & $(325401.19)$ & $(41441.01)$ \\
Poland & \multirow{2}{*}{290} & 164801.92 & 132421.59 & 6494.95 & 42163.52 & 9947.61 \\
& & $(232236.46)$ & $(188787.25)$ & $(8050.27)$ & $(122817.18)$ & $(33570.65)$ \\
Spain & \multirow{2}{*}{209} & 251121.16 & 149433.68 & 23639.69 & 76612.67 & 11306.51 \\
& & $(352022.93)$ & $(163434.71)$ & $(35626.74)$ & $(92205.68)$ & $(13956.47)$ \\
Eastern Europe & \multirow{2}{*}{426} & 148813.80 & 117962.82 & 6263.47 & 34812.74 & 7722.02 \\
& & $(198856.16)$ & $(161458.12)$ & $(7216.02)$ & $(102375.01)$ & $(27954.12)$ \\
Southern Europe & \multirow{2}{*}{555} & 272899.90 & 163364.77 & 26350.90 & 93322.57 & 13165.49 \\
Western Europe & \multirow{2}{*}{644} & $(605270.09)$ & $(321071.90)$ & $(67789.46)$ & $(263250.47)$ & $(33833.36)$ \\
& & 297610.13 & 222638.77 & 21353.52 & 48224.88 & 9946.32 \\
Whole sample & \multirow{2}{*}{1625} & $(451712.37)$ & $(346358.33)$ & $(33064.20)$ & $(76546.76)$ & $(24730.93)$ \\
& & 250163.11 & 174953.22 & 19104.40 & 60111.43 & 10462.68 \\
& & $(468908.84)$ & $(302136.22)$ & $(45577.75)$ & $(171185.22)$ & $(29012.56)$ \\
\hline
\end{tabular}

Note: Standard deviations are in parentheses.

sample. This data shows that the largest output value is exhibited by the average German dairy-manufacturing firm, while the smallest value was from the average firm in the Czech Republic. This data also indicates that dairy manufacturing firms in Western Europe have the largest values of output and material costs on average, while firms in Southern Europe have the largest values of employee costs, fixed assets, and investments. By contrast, firms in Eastern Europe exhibit the smallest values of all variables, on average. Despite focusing our analysis on large firms, the statistics in Table 1 show that there is still considerable variation in the sample, as indicated by the large values of standard deviations, relative to their respective averages.

\subsection{Results}

The empirical analysis was undertaken in two steps. First, we analyzed the results for our new dynamic weighted additive model that takes slacks into account, so projects on the strongly efficient frontier. We then compared the results of our new model with a dynamic model that does not account for slacks and projects on the weakly efficient frontier in the form of dynamic directional distance function (Silva et al., 2015; Kapelko et al., 2014; Ang \& Oude Lansink, 2014). ${ }^{9}$ We will refer to this latter model as a traditional dynamic model.

The inefficiency results were derived from a new dynamic model that takes slacks into account and a dynamic model that does not take them into account for each year separately. The computations were done with regard to the country-specific frontier and the pooled frontier, constituting all firms in the sample, regardless of country. We made both types of computations, due to the fact that inefficiency measures under group-specific technologies cannot be directly compared, while results under the pooled frontier can be directly compared since the pooled frontier covers all observations. Because of the considerable variation in the sample, as shown by the descriptive statistics in Table 1 , we decided to calculate inefficiencies with regard to the VRS frontier. The value of the directional vector used in computations of the traditional dynamic model is $g_{i 0}^{x}=x_{i 0}, i=1, \ldots, m$, for variable inputs, $g_{r 0}^{y}=y_{r 0}, r=1, \ldots, s$, for outputs, and $g_{h 0}^{I}=0.2 \cdot k_{h 0}, h=1, \ldots, f$, for

\footnotetext{
9 All DEA models were estimated using the GAMS program.
}

investments, which is in line with weights applied in the dynamic weighted additive model outlined in Section 3. Table 2 reports the average values of dynamic inefficiency derived from the dynamic weighted additive model per country and region, and for the whole sample in regard to country-specific and common frontiers. The significance of differences in inefficiencies between countries and regions is tested using Simar and Zelenyuk's (2006) test, denoted as the $S$ - $Z$ test. ${ }^{10}$

Table 2 shows that there are significant differences (in almost all cases) across countries, in terms of average values of dynamic technical inefficiency measured in relation to country-specific frontier. This result indicates that dynamic technical inefficiency under different group technologies is heterogeneous. When assessed with regard to own-country frontier, Poland is the most inefficient country, while the Czech Republic exhibits the lowest values of inefficiency. Moreover, Poland and Germany, and France, Italy, and Spain have the most similar levels of performance within their own groups.

Table 2 also shows that, in the majority of cases, there are significant differences between countries for the average values of dynamic technical inefficiency assessed in relation to pooled frontier. Not surprisingly, firms, on average, operate closer to their own-country frontier than to the common frontier that covers all firms in the sample, regardless of country. This is revealed by the lower values of dynamic inefficiency for the country-specific frontier for all countries in the sample. Western European countries (Germany and France) show the largest gap between countryspecific and common frontier, while Poland shows the most similar levels for country-specific and common performance. Interestingly, while Poland was the most inefficient compared to its own frontier, firms in this country were the most efficient group when assessed with regard to all firms in the sample. Therefore, on average, the best-performing companies in the pooled sample are mainly from Poland. In fact, when assessed with regard to pooled frontier, as compared to other countries, Poland has the highest number of

\footnotetext{
${ }^{10}$ In this analysis and also in the analysis contained in Table 3, we also applied another nonparametric test, namely the Wilcoxon test, and the results obtained replicate these obtained from the $\mathrm{S}-\mathrm{Z}$ test. In addition, as the $\mathrm{S}-\mathrm{Z}$ test is based on bootstrapping, we applied a different number of bootstrap replications (100, 500 and 1000) and the results of the test remain the same. Hence, the results of the tests can be considered as robust.
} 
Table 2

Dynamic inefficiency results per country and region, and for the whole sample, country-specific and common frontiers, 2005-2012.

\begin{tabular}{lll}
\hline Country & Country-specific frontier & Common frontier \\
\hline Czech Republic & 0.2217 & 1.6073 \\
France & 0.4149 & 1.9830 \\
Germany & 0.5449 & 3.2385 \\
Italy & 0.4228 & 1.4192 \\
Poland & 0.6122 & 0.9956 \\
Spain & 0.4273 & 1.0583 \\
Eastern Europe & 0.4876 & 1.1909 \\
Southern Europe & 0.4245 & 1.2833 \\
Western Europe & 0.4854 & 2.6636 \\
Whole sample & 0.4651 & 1.8061 \\
Significance (S-Z test) between & Yes, except of between Germany and & Yes, except of between \\
countries at the critical 5 percent level & Italy, and Germany and Poland & Italy and Poland \\
Significance (S-Z test) between regions & Yes, except of between Southern and & Yes \\
at the critical 5 percent level & Eastern & \\
\hline
\end{tabular}

Table 3

Dynamic inefficiency results - new model versus traditional model, 2005-2012.

\begin{tabular}{llllll}
\hline & \multicolumn{2}{l}{ Country-specific frontier } & & \multicolumn{2}{l}{ Common frontier } \\
\cline { 2 - 3 } \cline { 5 - 6 } \cline { 5 - 6 } Country & New model & Traditional model & & New model & Traditional model \\
\hline Czech Republic & 0.2217 & $0.0309^{* * *}$ & & 1.6073 & $0.1291^{* * * *}$ \\
France & 0.4149 & $0.0810^{* * *}$ & & 1.9830 & $0.1563^{* * * *}$ \\
Germany & 0.5449 & $0.0389^{* * *}$ & & 3.2385 & $0.1861^{* * * *}$ \\
Italy & 0.4228 & $0.0856^{* * *}$ & & 1.4192 & $0.1493^{* * *}$ \\
Poland & 0.6122 & $0.0522^{* * *}$ & & 0.9956 & $0.1116^{* * * *}$ \\
Spain & 0.4273 & $0.0579^{* * *}$ & & 1.0583 & $0.1409^{* * * *}$ \\
Eastern Europe & 0.4876 & $0.0454^{* * *}$ & & 1.1909 & $0.1172^{* * *}$ \\
Southern Europe & 0.4245 & $0.0751^{* * *}$ & & 1.2833 & $0.1461^{* * * *}$ \\
Western Europe & 0.4854 & $0.0582^{* * *}$ & & 2.6636 & $0.1724^{* * * *}$ \\
Whole sample & 0.4651 & 0.0606 & & 1.8061 & 0.1490 \\
\hline
\end{tabular}

${ }^{* * *}$ Denotes statistically significant differences between new and traditional model at the critical 1 percent level.

efficient firms relatively to all firms in the Polish sample (15 percent of efficient firms as compared to, for example, Czech Republic with 7 percent).

Table 3 presents the comparison of inefficiency results between the new dynamic model that incorporates slacks and a traditional dynamic model based on the dynamic directional distance function. The findings are reported per country and region, and for the whole sample, with regard to country-specific and common frontiers. Simar and Zelenyuk's (2006) test is used to assess the differences in inefficiencies between new and traditional models.

Table 3 shows that the application of a traditional dynamic model finds somewhat small values of inefficiency. The model projects on the weakly efficient frontier the majority of times. The findings reported in Table 3 also indicate statistically significant differences in average values of technical inefficiency between new and traditional dynamic models for the country-specific and pooled performance. In particular, the traditional model reveals smaller values of average inefficiency than the new model. Therefore, the weakly efficient frontier is quite far from the strongly efficient frontier in our sample of dairy-producing firms. This result seems to be logical, as the new model takes into account all sources of inefficiency, including slacks. Slacks as the sources of technical inefficiency are not considered in the traditional dynamic model, in contrast to our new model that always considers this type of inefficiency in its calculation. Hence, when projecting with slacks on the dynamic frontier, we find larger values of inefficiency than when projection is made without taking slacks into account. This finding seems also to be in line with previous literature, that in a static context reported considerably larger values of ineffi- ciency when an additive model was applied, which projects on the strongly efficient frontier, in comparison to the radial model, which projects on the weakly efficient frontier (see Pastor et al., 1999) ${ }^{11}$. Also in a static context, the literature reports different results for productivity change computed using directional distance function in comparison to productivity change based on the weighted additive model, which is due to the differences in the efficiency change component, that is, if projection on the production frontier is undertaken with or without slacks (see Aparicio, Borras, Ortiz, Pastor, \& Vidal, 2018).

However, in attempting to interpret the differences in inefficiency between both models more thoroughly, we compute inefficiency with regard to all variables (output, two variable inputs, and investments) using the new model. Table 4 reports these results. We can observe from the table that this heterogeneity in results between the new and the traditional model is mainly due to the inefficiency of investments. The values of inefficiency for output and two variable inputs are very similar to inefficiency found in the traditional dynamic model, while inefficiency of investments diverges considerably from the inefficiency reported by the traditional dynamic model. For example, the average countryspecific inefficiency for Germany is 0.0116 for output, 0.0085 for materials and 0.0337 for employee costs, while it is as much as 2.1259 for investments.

\footnotetext{
11 Although in our paper we talk about a dynamic model based on the directional distance function, a directional distance function model is still similar to a radial model, in the sense that both project on the weakly efficient frontier.
} 
Table 4

Dynamic input-and output-specific inefficiency results for the new model, per country and region, and for the whole sample, country-specific and common frontiers, 2005-2012.

\begin{tabular}{|c|c|c|c|c|c|c|c|c|}
\hline \multirow[b]{2}{*}{ Country } & \multicolumn{4}{|c|}{ Country-specific frontier } & \multicolumn{4}{|c|}{ Common frontier } \\
\hline & Output & Material costs & Employee costs & Investments & Output & Material costs & Employee costs & Investments \\
\hline Czech Republic & 0.0084 & 0.0163 & 0.0839 & 0.7783 & 0.0572 & 0.0106 & 0.0211 & 6.3403 \\
\hline France & 0.0344 & 0.0353 & 0.0557 & 1.5341 & 0.0806 & 0.0226 & 0.0785 & 7.7519 \\
\hline Germany & 0.0116 & 0.0085 & 0.0337 & 2.1259 & 0.0835 & 0.0402 & 0.0963 & 12.7341 \\
\hline Italy & 0.0354 & 0.0211 & 0.0757 & 1.5588 & 0.0712 & 0.0129 & 0.1008 & 5.4919 \\
\hline Poland & 0.0479 & 0.0066 & 0.1104 & 2.2841 & 0.0657 & 0.0155 & 0.0304 & 3.8707 \\
\hline Spain & 0.0226 & 0.0211 & 0.1020 & 1.5637 & 0.0713 & 0.0199 & 0.0921 & 4.0499 \\
\hline Eastern Europe & 0.0353 & 0.0097 & 0.1019 & 1.8034 & 0.0630 & 0.0139 & 0.0274 & 4.6591 \\
\hline Southern Europe & 0.0306 & 0.0211 & 0.0856 & 1.5606 & 0.0713 & 0.0156 & 0.0975 & 4.9489 \\
\hline Western Europe & 0.0220 & 0.0207 & 0.0438 & 1.8548 & 0.0821 & 0.0322 & 0.0881 & 10.4519 \\
\hline Whole sample & 0.0284 & 0.0180 & 0.0733 & 1.7409 & 0.0734 & 0.0217 & 0.0754 & 7.0538 \\
\hline
\end{tabular}

\section{Conclusions}

The paper develops the DEA-based, dynamic-weighted additive model that accounts for slacks when measuring dynamic inefficiency in the adjustment-cost theory framework. The paper also summarizes and proves the main properties of the developed model. Our new model allows for projecting inefficient firms to the strongly efficient, dynamic frontier, so estimates Pareto-Koopmans efficiency in the dynamic context. Moreover, it measures dynamic inefficiency in the full input-output space.

To illustrate, we applied the new approach to a recent dataset of large dairy-processing firms in the main dairy-producing countries in the EU from 2005 to 2012. The results revealed that there were considerable dynamic inefficiencies in the sample of dairy-producing countries. The comparison between the new approach that accounts for slacks and the traditional dynamic approach, based on dynamic directional distance function, indicates that there are differences in dynamic inefficiencies. The new approach shows more inefficiency, which proves to be caused mainly by the inefficiency of investments.

Future research efforts could focus on extending the dynamic weighted additive model developed in this paper to other measures within the family of weighted additive models such as, the range-adjusted measure (RAM) (Cooper et al., 1999), the boundedadjusted measure (BAM) (Cooper et al., 2011) or the slacks-based measure (SBM) (Tone, 2001). As future research, the general model developed in this study for the case of the full input-output space can be also converted into its input-oriented or output-oriented versions. Another important extension of the current study would be applying the dynamic weighted additive model to the context of measuring productivity change over time and incorporating slacks.

\section{Acknowledgments}

We thank three anonymous referees for providing constructive comments and help in improving the contents and presentation of this paper. Additionally, the authors appreciate the financial support from the Spanish Ministry for Economy and Competitiveness (Ministerio de Economia, Industria y Competitividad), the State Research Agency (Agencia Estatal de Investigacion) and the European Regional Development Fund (Fondo Europeo de Desarrollo Regional) under grant MTM2016-79765-P (AEI/FEDER, UE).

\section{References}

Aigner, D. J., Lovell, C. A. K., \& Schmidt, P. (1977). Formulation and estimation of stochastic frontier production function models. Journal of Econometrics, 6, 21-37. Aigner, D. J., \& Chu, S. F. (1968). On estimating the industry production function. American Economic Review, 58, 826-839.
Ang, F., \& Oude Lansink, A. (2014). Dynamic profit inefficiency: A DEA application to Belgain dairy farms. Working paper no 2014/3, Bioeconomics working paper series. KU Leuven.

Aparicio, J., Pastor, J. T., \& Vidal, F. (2016). The directional distance function and the translation invariance property. OMEGA, 58, 1-3.

Aparicio, J., Borras, F., Ortiz, L., Pastor, J. T., \& Vidal, F. (2018). Luenberger-type indicators based on the weighted additive distance function. Annals of Operations Research. doi:10.1007/s10479-017-2620-2.

Avkiran, N. K. (2009). Opening the black box of efficiency analysis: An illustration with UAE banks. OMEGA, 37(4), 930-941.

Banker, R. D., Charnes, A., \& Cooper, W. W. (1984). Some models for estimating technical and scale inefficiencies in Data Envelopment Analysis. Management Science, 30, 1078-1092.

Cazals, C., Florens, J., \& Simar, L. (2002). Nonparametric frontier estimation: A robust approach. Journal of Econometrics, 106, 1-25.

Chambers, R. G., Chung, Y., \& Färe, R. (1998). Profit, directional distance functions, and Nerlovian efficiency. Journal of Optimization Theory and Applications, 98, 351-364.

Charnes, A., Cooper, W. W., \& Rhodes, E. (1978). Measuring the efficiency of Decision Making Units. European Journal of Operational Research, 2, 429-444.

Charnes, A., Cooper, W. W., Golany, B., Seiford, L., \& Stutz, J. (1985). Foundations of Data Envelopment Analysis for Pareto-Koopmans efficient empirical production functions. Journal of Econometrics, 30, 91-107.

Chen, C.-M., \& Van Dalen, J. (2010). Measuring dynamic efficiency: Theories and an integrated methodology. European Journal of Operational Research, 203, 749-760.

Chen, C.-M. (2009). A network-DEA model with new efficiency measures to incorporate the dynamic effect in production networks. European Journal of Operational Research, 194, 687-699.

Cooper, W. W., Park, K. S., \& Pastor, J. T. (1999). RAM: A range adjusted measure of inefficiency for use with additive models, and relations to other models and measures in DEA. Journal of Productivity Analysis, 11, 5-42.

Cooper, W. W., Pastor, J. T., Borras, F., Aparicio, J., \& Pastor, D. (2011). BAM: A bounded adjusted measure of efficiency for use with bounded additive models. Journal of Productivity Analysis, 35, 85-94.

Dakpo, K.H. (2015). Non-parametric modelling of pollution-generating technologies: theoretical and methodological considerations, with an application to the case of greenhouse gas emissions in suckler breeding systems in French grassland areas. Doctoral thesis. Economies and finances. Université d'Auvergne - ClermontFerrand I.

Debreu, G. (1951). The Coefficient of resource utilization. Econometrica, 19, 273-292.

De Mateo, F., Coelli, T., \& O'Donnell, Ch (2006). Optimal paths and costs of adjustment in dynamic DEA models: With application to Chilean department stores. Annals of Operations Research, 145, 211-227.

Epstein, L. G. (1981). Duality theory and functional forms for dynamic factor demands. Review of Economic Studies, 48, 81-95.

European Commission. (2003). Recommendation concerning the definition of micro, small and medium-sized enterprises. Official Journal of the European Union, 124, 36-41. http://eur-lex.europa.eu/LexUriServ/LexUriServ.do?uri=OJ:L: 2003:124:0036:0041:EN:PDF. Accessed: February 2017.

Eurostat (2017). Short-term business statistics. http://ec.europa.eu/eurostat/web/ short-term-business-statistics/data/database Accessed: February 2017.

Färe, R., \& Lovell, C. A. (1978). Measuring the technical efficiency of production. Journal of Economic Theory, 19, 150-162.

Färe, R., \& Grosskopf, S. (1996). Intertemporal production frontiers: With dynamic DEA. Boston: Kluwer Academic Publishers.

Färe, R., Grosskopf, S., \& Lovell, C. A. K. (1985). The measurement of efficiency of production. Kluwer Nijhof Publishing.

Farrell, M. J. (1957). The measurement of productive efficiency. Journal of the Royal Statistical Society, Series A: General, 120, 253-281.

Fallah-Fini, S., Triantis, K., \& Johnson, A. L. (2014). Reviewing the literature on nonparametric dynamic efficiency measurement: State-of-the-art. Journal of Productivity Analysis, 41(1), 51-67. 
Kapelko, M., Oude Lansink, A., \& Stefanou, S. E. (2014). Assessing dynamic inefficiency of the Spanish construction sector pre- and post-financial crisis. European Journal of Operational Research, 237, 349-357.

Kapelko, M., Oude Lansink, A., \& Stefanou, S. E. (2017). Input-specific dynamic productivity change: Measurement and application to European dairy manufacturing firms. Journal of Agricultural Economics, 68, 579-599.

Kapelko, M. (2017). Dynamic versus static inefficiency assessment of the Polish meat-processing industry in the aftermath of the European Union integration and financial crisis. Agribusiness, 33(4), 505-521.

Koopmans, T. C. (1951). Analysis of production as an efficient combination of activities. In T. C. Koopmans (Ed.), Activity analysis of production and allocation. New York: John Wiley.

Lovell, C. A. K., \& Pastor, J. T. (1995). Units invariant and translation invariant DEA models. Operations Research Letters, 18, 147-151.

Luenberger, D. G. (1992). New optimality principles for economic efficiency and equilibrium. Journal of Optimization Theory and Applications, 75(2), 221-264.

Luenberger, D. G. (1995). Microeconomic theory. New York: McGraw-Hill.

Matin, R. A., \& Ghahfarokhi, M. I. (2015). A two-phase modified slack-based measure approach for efficiency measurement and target setting in data envelopment analysis. IMA Journal of Management Mathematics, 26(1), 83-98.

McLaren, K. (1980). Intertemporal duality: Application to the theory of the firm. Econometrica, 7, 1755-1762.

Nemoto, J., \& Goto, M. (2003). Measurement of dynamic efficiency in production: An application of data envelopment analysis to Japanese electric utilities. Journal of Productivity Analysis, 19, 191-210.

Nemoto, J., \& Goto, M. (1999). Dynamic Data Envelopment Analysis: Modeling intertemporal behavior of a firm in the presence of productive inefficiencies. Economic Letters, 64, 51-56.

Pastor, J. T., Ruiz, J. L., \& Sirvent, I. (1999). An enhanced DEA Russell graph efficiency measure. European Journal of Operational Research, 115, 596-607.

Pastor, J. T., \& Aparicio, J. (2015). Translation invariance in data envelopment analysis, chapter in data envelopment analysis. A handbook of models and methods. New York: Springer Verlag.

Rungsuriyawiboon, S., \& Stefanou, S. E. (2007). Dynamic efficiency estimation: An application to U.S. electric utilities. Journal of Business and Economic Statistics, 25(2), 226-238
Sengupta, J. K. (1995). Dynamics of data envelopment analysis: Theory of system efficiency. Dordrecht: Kluwer Academic Publishers.

Serra, T., Oude Lansink, A., \& Stefanou, S. E. (2011). Measurement of dynamic efficiency: A directional distance function parametric approach. American Journal of Agricultural Economics, 93(3), 756-767.

Shephard, R. W. (1953). Cost and production functions. Princeton: Princeton University Press.

Shephard, R. W., \& Färe, R. (1975). Dynamic theory of production correspondences. Research Report. Berkeley: University of California.

Simar, L. (2003). Detecting outliers in frontier models: A simple approach. Journal of Productivity Analysis, 20, 391-424.

Simar, L., \& Zelenyuk, V. (2006). On testing equality of distributions of technical efficiency scores. Econometric Reviews, 25(4), 497-522.

Silva, E., Oude Lansink, A., \& Stefanou, S. E. (2015). The adjustment-cost model of the firm: Duality and productive efficiency. International Journal of Production Economics, 168, 245-256.

Silva, E., \& Stefanou, S. E. (2007). Dynamic efficiency measurement: Theory and application. American Journal of Agricultural Economics, 89, 398-419.

Silva, E., \& Stefanou, S. E. (2003). Nonparametric dynamic production analysis and the theory of cost. Journal of Productivity Analysis, 19, 5-32.

Skevas, T., Oude Lansink, A., \& Stefanou, S. E. (2012). Measuring technical efficiency in the presence of pesticide spillovers and production uncertainty: The case of Dutch arable farms. European Journal of Operational Research, 223, 550-559.

Sueyoshi, T., \& Sekitani, K. (2005). Returns to scale in dynamic DEA. European Journal of Operational Research, 161, 536-544.

Tone, K. (2001). A slacks-based measure of efficiency in data envelopment analysis. European Journal of Operational Research, 130, 498-509.

Tone, K., \& Tsutsui, M. (2014). Dynamic DEA with network structure: A slacks-based measure approach. OMEGA, 42, 124-131.

Tone, K., \& Tsutsui, M. (2010). Dynamic DEA: A slacks-based measure approach. OMEGA, 38, 145-156.

Tone, K., \& Tsutsui, M. (2009). Network DEA: A slacks-based measure approach. European Journal of Operational Research, 197(1), 243-252.

Treadway, A. B. (1970). Adjustment costs and variable inputs in the theory of the competitive firm. Journal of Economic Theory, 2, 329-347. 